English Language and Linguistics, 25.1: 61-89. (C) The Author 2020. This is an Open Access article, distributed under the terms of the Creative Commons Attribution licence (http:// creativecommons.org/licenses/by/4.0/), which permits unrestricted re-use, distribution, and reproduction in any medium, provided the original work is properly cited.

doi:10.1017/S1360674319000443

\title{
The semantics of English out-prefixation: a corpus-based investigation $^{1}$
}

\author{
S VEN KOTOW S K I \\ Heinrich-Heine-Universität Düsseldorf \\ (Received 28 July 2019; revised 17 October 2019)
}

\begin{abstract}
The verbal prefix out- in its scalar-comparative sense is among the most productive English locative prefixes. Although several authors make use of the construction as a test environment for verb classification, few studies have looked at its semantics in any depth. Moreover, previous work on this prefix relies on fairly small databases or self-generated data, and no reliable corpus-based investigations are available, calling into question the usefulness of present semantic analyses and the application of the construction as a test environment.

This study aims at remedying these shortcomings via presenting a database culled mostly from COCA and iWeb. Based on the analysis of the wide range of attestations in the database it is shown that existing generalizations and previous semantic analyses are wrong and that particular restrictions proposed in the literature are not borne out by the data. Several claims, including core features of the formalizations offered in the literature, have to be discarded. Furthermore, alleged base-restrictions on the input out-allows are shown to be far too restrictive. This holds for verbal as well as adjectival and nominal bases. It is shown that approaches that deny the existence of category-changing prefixes are misguided.

Overall, the construction is more flexible regarding possible interpretations and more promiscuous with respect to possible bases than previously thought. At the same time, the system is not unrestricted. Generalizing over the data, this article lays out the requirements and specific challenges any full formal account of out- will have to match.
\end{abstract}

Keywords: derivational semantics, English prefixes, word-formation, corpus linguistics, complex verbs

\section{Introduction}

English has a relatively large inventory of locative prefixes that are used for expressing spatial, temporal or scalar-quantificational concepts. Bauer et al. (2013: ch. 16) enumerate 38 such prefixes in total, most of which are of prepositional origin and still do double duty as prepositions in the case of native prefixes (e.g. down-, in-, up-) or derive from non-native prepositions (e.g. inter-, post-, sub-). As prefixes, these have

\footnotetext{
${ }^{1}$ I thank Ingo Plag, Martin Schäfer and two anonymous reviewers for valuable criticism and comments on this article. This work has partly been funded by the German Research Foundation (DFG)/CRC 991 'The Structure of Representations in Language, Cognition, and Science'/Project C08 'The semantics of derivational morphology: A frame-based approach'.
} 
been largely neglected in the literature on English derivational morphology (but see, e.g., Williams 1992; Lehrer 1995; Bauer 2003; Lieber 2004: ch. 4; Bauer et al. 2013: ch. 16). Among the most productive of these is out- (see Schröder 2011), which gives rise to at least the syntactic and semantic categories in (1) (data from COCA, see Davies 2008; Bauer et al. 2013; OED 2018). The semantic labels are informal, the list is not necessarily exhaustive and doublets in the data show that different output categories can occur with the same bases:

(1) (a) locative nouns outhouse, outstation, out-group ${ }^{2}$

(b) locative verbs to outhouse, to outsource, to out-marry

(c) locative participle adjectives out-hanging, outstretched, outcurved

(d) comparative verbs to outrun s.o., to out-marry s.o., to outstubborn s.o.

This study will focus on the comparative verb pattern in (1d), which I will call OUT-PREFIXATION in the remainder, using additional labels for other prefix senses. The construction exhibits a number of well-known peculiarities that pose challenges to formal morphological, syntactic and semantic analyses. Marchand (1969), Williams (1992) and Bauer \& Huddleston (2002) treat out-prefixation as compounding with prepositional non-heads. I will follow Bauer et al. (2013: 340), who regard induced argument structural effects, not perfectly coextensive semantic contributions of free forms and their homophonous counterparts in complex words, and clear mismatches in the productivity of senses as indicative of prefixhood. Accordingly, out- patterns as a prefix rather than as a compound non-head.

Let us look at some general properties of out-prefixation:

(2) (a) On and off camera, more girls are dishing about discharge, outfarting their friends, and taking part in other beyond-ribald behavior. (COCA)

(b) We try to outdrink our friends and end up as alcoholics. (COCA)

(c) We often try to outdrink ??(our friends) (??the beer).

In general, out-prefixation generates transitive structures and has applicative potential, i.e. it can license unselected Objects (see Wunderlich 2012 for an overview). If the base verb is intransitive to begin with, as in (2a), an NP-argument is added. If the base verb occurs regularly transitively, the Object-NP-argument can differ in semantic category from the Objects typically licensed by the base verb, as in (2b). At the same time, (2c) shows that out-prefixation does not allow the additional realization of Objects otherwise licensed by the base verbs (cf. Bauer et al. 2013: ch. 16). As will be shown below, the nature of possible Object-arguments is a rather intricate issue.

2 Throughout this study, I will not make any claims regarding potential differences between hyphenated and non-hyphenated usages of out-. This does not mean that such differences do not exist, possibly in the realm of lexicalization and frequency only, but that structural or interpretational differences are difficult to discern. For example, the lemma outJuMP is attested in COCA 19 times, while the lemma ouT-JUMP is attested 5 times, with no traceable meaning difference between these two uses. 
As in (3), comparative out-prefixation appears to be among the few category-changing prefixes in English:

(3) (a) I mean, you can't out-Republican the Republicans. (COCA)

(b) He would do one pose, and I would try to out-absurd him. (COCA)

Neither Republican nor absurd are attested as verbs in the $O E D$, nor do they occur with a verbal part-of-speech tag in COCA. Out- is thus among the apparent exceptions to the Righthand Head Rule (see Williams 1981): in the majority of cases, suffixation in English is category-determining, while prefixation is category-preserving (cf. Plag 2003, 2004; Nagano 2011).

Regarding the core semantic contribution of out-, two approaches can be distinguished, which I will call COMPARATIVE and RESULTATIVE, respectively. Most authors paraphrase the construction's meaning as ' $X$ better/more/longer than $Y$ ' or 'have higher/better/more $X$ than $Y$ ', i.e. a rough interpretation of 'exceeding, surpassing' (cf., e.g., Bauer \& Huddleston 2002: 1679). This suggests that the construction primarily denotes comparison. However, several authors stress that in the majority of cases comparison entails competition and that out-prefixation gives rise to the interpretation that the Object-argument is defeated in said competition (see, e.g., Marchand 1969: 96; Talmy 2000: 260; McIntyre 2003: 122f.). Consider (4):

(4) The trick here is to outsit your neighbors. Lots of hunters get tired and antsy after spending many hours in a stand, and start coming down to the ground by 10 a.m. or so. (COCA)

Following the comparative analysis, outsit your neighbors in (4) is naturally interpreted as a comparison between hunters, with one hunter sitting on a stand longer than her competitors. In turn, the resultative analysis profiles a slightly different aspect: the competition between hunters, in which one participant is outdone or defeated by sitting on a stand less long than her competitor. Although these views appear as essentially two sides of the same coin, they do make different predictions regarding the assumed sub-events and their participants. As shown in (5), this dual nature is also reflected by a number of presumably different senses the $O E D$ acknowledges for out- as a verbal prefix. These senses are, in fact, difficult to disentangle and are, partly, attested with the same base verbs (see OED 2018: out-, prefix):

(5) (a) [sense 4.a.(a)] To pass beyond or exceed (a defined point, a limit in space, time, degree, etc.), by or in the action expressed by the simple verb: e.g. outlast, outrun

(b) [sense 4.a.(bi)] To surpass, excel or outdo (a person, etc.) in the action of the simple verb: e.g. outlive, outrun

(c) [sense 4.a.(bii)] To get the better of, overpower, or defeat in a direct competition involving the action of the simple verb: e.g. outbrawl, outcompete

(d) [sense 4.a.(biii)] To overcome or defeat by the action of the simple verb: e.g. out-blur, out-buzz 
Several authors make use of out-prefixation as a diagnostic for verb classification (e.g. Bresnan 1982; Keyser \& Roeper 1984; Levin 1999; Beavers \& Koontz-Garboden 2012; Baker 2019). Yet very few studies have looked at the construction's semantics in any depth (but see Williams 1992; Talmy 2000; Tolskaya 2014; Ahn 2016). This is an unfortunate state of affairs, as the attested data present themselves as more heterogeneous than oftentimes assumed. As I will show below, the semantics are far from well-understood, calling into question the usefulness of utilizing the construction as a test environment for verb classification.

This article aims at a better general understanding of the semantics of out-prefixation by dint of providing a larger set of data culled from copora (mostly from COCA and iWeb; Davies 2018). Unlike the majority of publications on the phenomenon, this study is thus not based on self-generated (or rehashed) data or on intuitions about their acceptability. Rather, the focus is on providing an overview based on actual, attested use in corpora. The article discusses the extent to which these data are in line with theoretical predictions and evaluates proposals made in the literature, both on the construction's general semantics and its selectional restrictions. The methodological approach of juxtaposing corpus data and theoretical treatments is thus similar to the one outlined in Lieber (2016: ch. 2.2) for other morphological phenomena. The present study is based on a data set of more than 600 types and more than 900 tokens of out-prefixed verbs. As will be shown, a number of predictions from the literature have to be discarded, while new generalizations emerge. In particular, out- is far more promiscuous than often assumed regarding the input it allows and attested corpus examples often show a range of related possible interpretations even for the same bases.

The article is structured as follows: section 2 sketches previous approaches. Section 3 evaluates and discusses these previous approaches with the help of corpus data. Similarly, corpus data are used critically in the discussion of several alleged selectional restrictions in section 4. Section 5 evaluates the overall findings, generalizes them and provides an outlook. Section 6 concludes.

\section{Previous approaches}

Broadly speaking, two different kinds of analysis have been proposed for the semantics of out-prefixation: while most authors opt for a comparative approach, the minority view stresses the construction's resultative nature. This section will briefly recapitulate these approaches. I will show in section 3 below that, in their strong versions, neither approach is capable of fully and adequately capturing the range of attested interpretations. Let us start with approaches that focus on comparison.

\subsection{Comparative approaches}

Syntax-based treatments in the literature do not always understand comparison in terms of scalarity. In contrast, the semantics literature on out- often makes explicit use of scales in their analyses. Following the reasoning of Bierwisch (1989: 112), scalarity and 
comparison are inescapably intertwined: 'there is no degree without comparison and no comparison without degrees'. Therefore, the cover term SCALAR-COMPARATIVE will be used in the following for both of these comparative approaches. I will, following standard treatment, consider scales triples of information: (i) a DIMENSION of measurement such as SPEED, TEMPERATURE, HEIGHT etc.; (ii) a set of DEGREES along said DIMENSION; and (iii) an ORDERING RELATION among those DEGREES (see, among many others, Kennedy \& McNally 2005; Kennedy 2007; Solt 2015). Following Löbner (1979: 173), dimensions are taken as sets of 'mutually exclusive properties of which an individual has exactly one at each point in time'.

Although couched in different frameworks by different authors, the scalar-comparative approach is characterized by the assumption that two events of the same kind are being compared. The construction's core meaning contribution, then, is that the Subjectargument exceeds or surpasses the Object-argument with respect to some dimension encoded in these events (see, e.g, Bresnan 1982; Irube 1984; Williams 1992; Talmy 2000; Bauer \& Huddleston 2002; Tolskaya 2014; Baker 2019). According to this view, for example, to outrun someone means, depending on context, to run faster, farther, in some way better etc. than someone. The alleged requirement that Subjectand Object-arguments have to fulfill the same thematic role of the same kind of event at some level will be called the SAMENESS CONDITION in the following. Stating such a condition for the events to be compared is taken as necessary to prevent over-generation. As Talmy (2000: 260) puts it, the events have to be the same, 'so that there is no *I outplayed the singer in the sense that I played better than the singer sang'. Along the way, such analyses (implicitly) claim to unravel the mystery of unselected Objects common to out-prefixed verbs, i.e. its applicative nature: Objects 'merely' provide a standard of comparison. This is apparently unproblematic in many cases, such as the ones in (6) (both from iWeb):

(6) (a) They were both running, but John outran Peter and reached the tomb first.

(b) Took second-place in the triple jump (51-7.25) as he was out-jumped by a $1 / 2$ inch on the final attempt by Iowa's Babatunde Amosu.

Given such seemingly straightforward interpretations, Irube (1984) and Baker (2019) advocate non-scalar comparative approaches in (generative) syntactic frameworks. For example, Irube (1984: 114) is fairly explicit in assuming possible comparative paraphrases for out-prefixation constructions as in (7):

(7) (a) Outfielders must outthrow infielders. [=ex. 17a in Irube 1984]

(b) Outfielders must throw farther than infielders. [=ex. 17b in Irube 1984]

Such analyses assume out-prefixation to function similarly to regular comparison, which is presumably derived via deletion of material in the lower clause: Outfielders must throw farther than infielders throw (see Schwarzschild 2008: 320ff.; Stassen 1985: ch. 9.4.2 for arguments in favor of such analyses for English comparatives in general). While there may be differences between Irube (1984) and Baker (2019) regarding the status of the respective second occurrences of the lexical verb, the predictions are decidedly clear: 
the two events being compared have to be of the same kind, as they both are, in fact, (covertly) realized at some point during sentence derivation.

Related approaches make concrete use of the notion of scales. Williams (1992), Talmy (2000) and Tolskaya (2014) all regard out-prefixation as a metaphorical extension of a FIGURE-GROUND-PATH-constellation underlying the literal movement in space in other uses of out. The metaphor's target domains, then, are scales or containers that allow for comparison between two events, with the Subject-argument functioning as FIGURE that moves (literally or figuratively) along and surpasses a point on a scale provided by the Object-argument functioning as GROUND. For example, Talmy (2000: ch. 3) includes out-prefixation in his typology of event integration as an instance of conflation. ${ }^{3} \mathrm{He}$ assumes that certain constructions consisting of a satellite and a single verb stem give rise to integrated complex events. Talmy discusses out-prefixation as one of his CORRELATING ACTION constructions as in (8), where IN-SURPASSMENT-OF constitutes a framing event encoded in the prefix, which is in turn CONSTITUTED-BY a co-event encoded in the verbal base. Thus, the construction's meaning boils down to comparing two correlated events, where the implicit event the Object-argument participates in 'is limited to being the same as that of the Agent, not just to being of the same category' (Talmy 2000: 260):

(8) out-V NP 'surpass/best/beat NP at Ving' [I ACTed IN-SURPASSMENT-OF him] CONSTITUTED-BY [I played (the melody)] English: I outplayed him. [=ex. 35 in Talmy 2000]

In the spirit of scale-based approaches to verbal prefixation in Russian (see also Kagan 2015; Zinova 2016), Tolskaya (2014) also subscribes to the PATH= SCALE-metaphor, but is more explicit regarding her use of scalar dimensions. On her view, out- introduces a threshold encoded by an underlying event the Object-argument participates in, which is then exceeded with respect to some dimension by the Subject-argument participating in an event of the same kind. She suggests two different functional projections dedicated to two distinct scales that the respective Subjects and Objects map to. Objects are participants of the second scale and are co-indexed with the out-verb's projection, ensuring that both participants fulfill the same roles of the same verbs. Less committed to scalar representations, Ahn (2016) makes similar use of neo-Davidsonian representations to spell out the semantics of functional argument projections. Unlike Talmy, he does not restrict possible thematic roles to AGENTS, but assumes a more general constraint that ensures that both internal and external argument are assigned the same thematic roles with respect to the same underlying event(s).

${ }^{3}$ Following Talmy, conflation structures form a large family of lexicalization patterns. Other such patterns include, for example, MOVE + MANNER as in I bounced the keg into the storeroom, or MOVE + CAUSE as in I chopped the tree to the ground, where the respective PPs are headed by satellites encoding the framing event, while the lexical verbs provide information on the co-events MANNER and CAUSE, respectively; cf. Talmy (2000: 30). See also Wunderlich (1997) and Rappaport Hovav \& Levin (1998) for different terminology for essentially the same phenomena. 
The basic commonalities of the approaches introduced thus far will be crucial for the discussion of the data in section 3: out-prefixation is comparative and imposes a sameness condition on the underlying events, so that both Subject and Object are assigned the same thematic roles. This differs from the predictions made by the resultative approach to which we turn now.

\subsection{The resultative approach}

The second approach to out-prefixation, advocated by McIntyre (2003) and Nagano (2011), is an essentially resultative analysis. Based on structural similarities with constructions commonly analyzed as resultative (see, e.g., Jackendoff 1997; Rappaport Hovav \& Levin 2001; Goldberg \& Jackendorf 2004), McIntyre (2003: 122-4) and Nagano (2011: 74f.) consider out-prefixed-verbs resultative accomplishments. McIntyre, for example, discusses out- alongside other English and German 'preverbs', i.e. both prefixed and particle verbs, and argues that a broad range of these can be considered resultative (see also Stiebels 1996; McIntyre 2007; Los 2008). Similarly to Talmy (2000) above, he analyzes the construction as an instance of event conflation, in which a single VP has the capacity to express two causally related events. The semantic representations provided are then intended to capture the similarities:

(9) (a) Dave ate himself sick. [=ex. 5b in McIntyre 2003]

(b) DO(DAVE,EAT) $\&_{\text {CAUSE }}$ BECOME(SICK(DAVE))

(c) Fred outdrank Stan. [=ex. 8b in McIntyre 2003]

(d) DO(FRED,DRINK) $\&_{\text {CAUSE }}$ OUTDONE(STAN)

Thus, the analysis claims to capture the occurrence of unselected Objects in a fashion similar to common resultatives: out-prefixation creates complex verbs and Objects are introduced into the structure as participants of sub-events. Although neither McIntyre (2003) nor Nagano (2011) are explicit regarding paraphrases that would concretely capture the resultative nature in prose, the implicit claim appears to be that Fred outdrank Stan does not primarily mean 'Fred drank more than Stan' (see the comparative approaches above), but something along the lines of 'Fred drank and thereby Stan was outdone'. Obviously, this analysis disposes of any notion of event comparison: in other words, the interpretation that Stan also drank in the depicted event is not made transparent in the semantic structure in (9d). For this reason, McIntyre (2003: 123) suggests that the competition-reading is essentially a historical accident or idiosyncratic part of out's meaning.

The general predictions made by the two approaches, scalar-comparative and resultative, respectively, can be summarized as follows: on a comparative approach, the Object-argument serves as a necessary, and therefore syntactically obligatory, threshold to be exceeded by the Subject-argument, while both participants engage in an event of the same kind. On a resultative analyses, unselected Objects receive an explanation via the introduction of a new sub-event that is caused by an event the Subject-argument participates in. At the same time, the comparative nature cannot immediately be read 
from the assumed semantic structures. The following section aims at providing some empirical flesh to the bones, showing that both analyses fall short of empirical adequacy.

3 The general interpretation(s) of out-prefixed verbs

This section approaches the general meaning of out-prefixation via a range of attested corpus data. The predictions of previous accounts as introduced above are critically discussed against these data, showing that all of these approaches have to be partly dismissed. Assigning out-prefixation one and only one general semantics is far from straightforward, as attested examples in fact present themselves in different guises. Analyzing the core meaning is to a degree caught in the tension between comparative and resultative semantics. Example (4), repeated here as (10), serves as illustration again:

(10) The trick here is to outsit your neighbors. Lots of hunters get tired and antsy after spending many hours in a stand, and start coming down to the ground by 10 A.M. or so. (COCA)

The tension arises from the dual nature of the interpretation of such examples: (i) the interpretation that the Subject (implicit here) surpasses the Object in V-ing, and (ii) the interpretation that the Object thereby loses out in a competition (see also the different senses the $O E D$ lists in (5)). Let us first turn to the question of how comparison arises and what it is that is actually being compared. For this, a closer look at scalar dimensions is necessary.

\subsection{Comparison is based on scalar dimensions}

As acknowledged by some authors (e.g. Tolskaya 2014: 8), and as shown in (11), there is some variability regarding the dimension that forms the basis of comparison (all data from iWeb):

(11) (a) The German Me 262 jets could outfly the Mustangs by 100 MPH in level flight.

(b) The point of A-Wing interceptors wasn't technically combat superiority. There are better interceptors [...] In terms of maneuverability, there wasn't much that could outfly one.

(c) The Blackjack's 5 control lines makes it easy to turn on toggles [...] The glide ratio is superb and I'm usually able to out-fly my mates who fly competing brands.

(d) Good vocal control is essential, a backing singer must not try to 'outsing' the lead vocalist $[\ldots]$ Whilst most sound engineers and producers will adjust vocal volumes in the mix, it is important for singers who have strong voices to remember to back off the microphone a bit...

(e) LBT is my guilty pleasure, you can't deny their vocal abilities. Have seen them live and nobody out there can outsing them from a technical standpoint.

As shown by the underlined contextual information in (11), to outfly is attested as referring to at least the dimensions of SPEED in (11a), MANEUVERABILITY in (11b), and DISTANCE in 
(11c). To outsing, in turn, is attested with at least LOUDNESS in (11d) and QUALITY in (11e). The examples in $(12 \mathrm{a}, \mathrm{b})$ show that the scales in question do not have to be a property scales, such as SPEED or LOUDNESS, but can also refer to cardinalities (see also Tolskaya 2014; cf. Solt 2015 for the difference between property and cardinality scales):

(12) (a) We currently have a kitten who is quickly becoming a cat who is outeating, both in terms of meal size and meal frequency, all of the other cats in our family. ${ }^{4}$

(b) Between 30 and 40 drug bosses have carved up the city and easily outgun the police with their arsenals. $(O E D)$

(c) If he has a rifle and you try to outgun him with a pocket pistol rather than run for cover you are stupid. (iWeb)

In (12a,b), meal frequency and the arsenals indicate abstraction over multiple events or entities, i.e. cardinality or frequency of occurrence. In turn, meal size in (12a) as well as (12c) show that both outeat and outgun are also compatible with property scales. The data presented so far are already an indication that the basis of comparison is not the verb itself. Rather, it is possible scalar dimensions that verbs are compatible with, the frequency with which certain events occur, or how they quantify over entities. Although dimension-based comparison is not what comparative approaches (e.g. Tolskaya 2014; Ahn 2016; Baker 2019) predict, this is not necessarily problematic for any of the theoretical approaches sketched above. However, as shown in section 2, comparative approaches also assume a sameness condition on eventualities to hold. The following shows that this condition makes wrong predictions.

\subsection{The sameness condition}

All comparative approaches assume the two events in out-prefixation-contexts to be the same. Considering examples such as (13), this sameness condition is empirically inadequate:

(13) (a) Hippos cannot swim, which is one interesting fact about them. But when they chase you, they will basically run underwater, and they can move around 5 mph. This can be faster than you think. They also don't tire easy, so you better have good cardio to outswim one. (iWeb)

(b) "I wasn't going to run," Mr. Paxton said later after the game. "I figured I'm not going to outrun an eagle, so we might as well just see what happens."

(c) The flow is a slow drawl to fit with the song and I like that you're not outrapping the beat. (iWeb)

(d) "Its [sic] a good time to retire in 2017 if you feel ready to leave your job and if you have done a thorough financial analysis as to your ability to not outlive your money," said Jones. (iWeb)

\footnotetext{
${ }^{4}$ Schwartz, G. 2012. Biology of eating behavior in obesity. Obesity Research 12, $105 \mathrm{~S}$.

5 https://forbes.com/sites/grrlscientist/2018/04/08/why-did-the-eagle-land-on-seattle-mariners-pitcher-james-paxton/
} 
The data in (13) all show that the sameness condition makes wrong predictions, as the arguments in Object position are not necessarily potential (Subject-)arguments of the verbal base. In (13a), the speaker explicitly claims that hippos cannot swim but still allows them to be outswum. Example (13b) at least clearly suggests a possible contest between a running Mr. Paxton and a flying eagle. Both beat and money in $(13 \mathrm{c}, \mathrm{d})$ do not make good Subjects of to rap and to live, respectively, violating the verbs' selectional restrictions. Thus, non-scalar comparative analyses (see Irube 1984; Baker 2019) that rely on deletion of base verbs have to be discarded. Having said that, the generalization appears similar to the one for the data in (11): comparisons are made based on dimensions (see Stiebels 1996: 69f. for similar observations regarding German über- 'over'). Thus, in (13a), in the domains DISTANCE/SPEED, in (13b,c) most likely in SPEED and in (13d) in DURATION.

At the same time, it seems obvious that comparisons cannot be made regarding any two kinds of event, as long as there is a possible dimension-match to be construed. For example, the (underlying) verbs from (13a,b), to swim, to fly, and to run, are all from the domain of LOCOMOTION, and cluster together in verb classifications such as VerbNet (see Levin 1993; Kipper et al. 2008). In contrast, creating an out-prefixation-context that compares a RUNNING- and a RAPPING-event regarding the respective speeds with which they are carried out by their AGENTS appears decidedly odd, as in (14b). This appears to hold, although the respective verbs in question do allow for speed-related manner-modification and, as shown in $(13 \mathrm{~b}, \mathrm{c})$, in principle allow for accessing the SPEED-dimension in out-prefixation-contexts.

(14) (a) John ran/rapped fast. [Modification with a SPEED-adverb]

(b) ??John is a fast runner and Kim is a fast rapper, but John outruns her every time. [On the reading that John runs and Kim raps]

The reason for the acceptability of the examples in (13) and the oddness of (14b) is found in the (dis)similarity of the respective events. It appears possible to establish a comparison along the SPEED-dimension between, say, a RUNNING- and a SWIMMING-event, because both of the events denote an entity's movement through space. In turn, mere compatibility with some dimension is not enough to license out-prefixation - and at least the minimal context provided in (14b) does not allow for easily finding a suitable threshold that could serve as comparative basis for a RUNNING-event. ${ }^{6}$ This is reminiscent of the little-understood restrictions on comparison in general, known as INCOMMENSURABILITY in the literature (cf. Kennedy 1997; Doetjes 2010). The generalization, then, is that it is scalar dimensions, and not concrete verbs, along which comparisons are made, while the underlying event properties still have to display a certain degree of similarity.

The sameness condition is therefore wrong if conceived of as either verb-based or analyzed in the form of co-indexation of events (or some form of covert double

${ }^{6}$ In contrast to the general methodological approach advocated here, the examples in (14) are made up. It is obviously an empirical question whether such asymmetrical comparisons are not attested at all in (probably substantially) larger contexts, but no cases of this nature exist in my database. 
realization). Still, the examples discussed so far all allow for clearly comparative readings. The picture is, however, further complicated by the data we turn to in the next section, as these partly elude comparison altogether, be it based on concrete verbs or dimensions.

\subsection{Unavailability of comparison, coercion and ad hoc result states}

The data in (15) are difficult to straightforwardly reconcile with a comparative approach based on scalar dimensions:

(15) (a) Whatever you do to stay active this summer, make sure to stay hydrated and to properly fuel with healthy meals pre and post-burn. And remember, you can never outrun a crappy diet! (iWeb)

(b) Yesterday's primitive market had built-in instability [...] Today, however, we finally have enough digital horsepower to out-compute all the market's vagaries. (COCA)

(c) [The jacket] disperses moisture for enhanced breathability. And, if you do outsweat the jacket, it has large pit zips to dump heat and aid in getting your internal ecosystem under control. (iWeb)

(d) Michael beat em. Michael rose to the top. He out-sang his cynics. He out-danced his doubters. He out-performed the pessimists. (iWeb)

(e) So far, my encounters have relied on me out-witting and out-sneaking the fierce-looking rat guards, or occasionally lobbing a bottle at their heads to knock them out while I get away. (iWeb)

Natural interpretations of the examples do, in fact, suggest a high degree on some scale for RUNNING-, such as FREQUENCY or AMOUNT in (15a), or COMPUTING-events, for example STRENGTH Or QUALITY in (15b). The problem that arises with comparison-based analyses for the examples in (15) lies in the nature of the Object-argument's contribution: clearly, crappy diets and the market's vagaries cannot run (or move) and compute, respectively (similarly, jackets do not sweat or can easily be construed as THEMES of SUBSTANCE EMISSION-verbs). In turn, it is not a matter of selectional restrictions but of contextual information that suggests that the cynics in (15d) do not sing themselves, while the guards in (15e) do not sneak.

On the assumption that the constructional meaning of out-prefixation is always comparative in nature, we would expect the Object-arguments to be coerced (cf. Asher 2011; Maienborn 2019) into suitable thresholds for some dimension that is compatible with the base of out-. A coercion-analysis seems feasible for $(15 \mathrm{c}, \mathrm{d})$ : the jacket (or its lining, rather) can relatively easily be construed as a container for liquids with a maximum holding capacity, which can then be exceeded. Similarly, the cynics from (15d) can possibly be reinterpreted as having or voicing certain expectations regarding Michael's qualities as a singer, which, again, can then be exceeded. Such analyses are less suitable for the other examples above: for example, arguing that the rat guards in (15e) are coerced into a particular degree of attention level, which is then 'exceeded' by sneaking particularly well/silently, does not appear very convincing. Similarly, a 
crappy diet in (15a) would have to be reinterpreted as its own consequence, some poor state of health, which can only be improved via a certain AMOUNT of running.

Such cases of out-prefixation appear to primarily contribute causative-resultative semantics (cf. McIntyre 2003; Nagano 2011): the Object-argument is OUTDONE or BEATEN as an effect of the Subject-argument's involvement in the event denoted by the verbal predicate. The respective result states of the Object-arguments are then context-dependent and, to some degree, ad hoc properties (cf. Barsalou 1983; Maienborn 2007). For example, in (15a,b), the crappy diet and the market's vagaries are DEFEATED or their effects NULLIFIED, in (15c) the jacket is OVERFULL, while in (15d,e) the cynics are HUSHED and the guards TRICKED. Context-dependence is important insofar as neither the base verb nor some other element in the construction concretely spells out the nature of a possible result state: for example, except for the prefix out- itself, there is no lexical material in (15a) that suggests the effects of a crappy diet to be NULLIFIED. In turn, the notion of an ad hoc property or state appears equally crucial here: resultative constructions, as well as verbs believed to entail result states, are often assumed to display concrete CHANGES-OF-STATE or LOCATION (cf. Rappaport Hovav \& Levin 2001; Goldberg \& Jackendorf 2004), as in The lake froze solid or John hammered the metal flat. Therefore, the respective arguments are usually regarded as PATIENTS (cf. Jackendoff 1997) or FORCE-RECIPIENTS (cf. Rappaport Hovav \& Levin 2001). With the exception of (15c), outsweat the jacket, none of the examples in (15) suggest concrete physical changes-of-state, but the rather weakly resultative notion of 'being on the losing end'.

This does not imply that the CORRELATING-pattern argued for by Talmy (2000) for out- is inappropriate (see section 2). All of the examples in (15), as well as all other attestations discussed, suggest the respective Object-arguments to be participants of eventualities other than the caused change-of-state. Just as He out-sang his cynics in (15d) includes a BE CYNICAL-event the cynics are the AGENTS of, the jacket in $(15 \mathrm{c}$ ) is the THEME (or the POSSESSOR) of a HOLDING CAPACITY-state. Besides evidence against the sameness condition on (agentive) events, Subject and Object can thus also be participants of eventualities that are aspectually and conceptually fairly distinct.

Importantly, most of the clearly comparative cases described above by no means preclude causative-resultative analyses of this weaker kind. For instance, examples such as the ones repeated here as (16) quite naturally receive resultative interpretations in addition to comparisons based on scalar dimensions:

(16) (a) The glide ratio is superb and I'm usually able to out-fly my mates who fly competing brands.

(b) Good vocal control is essential, a backing singer must not try to 'outsing' the lead vocalist $[\ldots]$

In case this is the correct generalization, it also entails that, conceptually, we are dealing with three sub-events in out-constructions: a CAUSE, of which the Subject is the sole participant, the EFFECT, i.e. a CHANGE-OF-STATE, and a CORRELATING EVENTUALITY-sub-event. 
The latter two sub-events, CHANGE-OF-STATE and CORRELATING EVENTUALITY, take the Object as participant.

\subsection{Summary: an interpretational cline}

The previous subsections have argued for a co-occurrence of comparative and resultative interpretations in the majority of examples. Importantly, clear-cut resultative readings appear stronger the more clearly Subject- and Object-argument compete or the more the Object-argument is affected by the Subject's action. In turn, the sense of resultativity is weaker the more abstract the event participants are or the less clear a competition between them appears (see also Talmy 2000: 260 for a similar observation). Rather than arriving at one hard-and-fast rule regarding the interpretation of out-prefixed verbs, generalizations will have to accommodate a sort of interpretational cline: the range of possible interpretations is context- and participant-bound rather than primarily driven by the base.

This is illustrated in (17), which shows that the same input-verb to vote can give rise to the different kinds of reading introduced in this section. In (17a), construals of a competition and, consequently, a result state the Object enters are weak, with a numerical sense of comparison dominating. This latter reading is also present for (17b), but the sense of the US losing out in the vote in question is readily available. Yet again different is the natural interpretation of (17c), where the resolution does not vote itself (if anything, it is the THEME of the voting-event). Thus, a less controversial result-state, BEING REJECTED, dominates (all from COCA):

(17) (a) In the 1988 presidential election, Hispanic women outvoted Hispanic men 52 percent to 48 percent, according to a survey...

(b) The United States, for the first time, in history, has no veto power. We have no weighted voting. We can be outvoted by two small countries.

(c) In 1998, a group of Dominican nuns [...] showed up at the annual GE shareholders meeting to demand the company educate the public about the risks of its discharge of industrial waste into local rivers. The resolution was outvoted...

Unsurprisingly, then, environments that are claimed to test for resultativity or Object-affectedness yield different results. For example, applied to the examples in (17), the What-happened-to-Y- and What-X-did-to-Y-tests (see, e.g., Jackendoff 1997; Rappaport Hovav \& Levin 2001) yield diverging results. ${ }^{7}$ These results mirror the different interpretations regarding the clearness of a conventional result state:

(18) (a) ??What happened to Hispanic men was Hispanic women outvoted them. / ?? What Hispanic women did to Hispanic men was outvote them. [compare (17a)]

\footnotetext{
7 This obviosuly does not imply that all out-verbs show the same behavior with this or the tests used below. For
} example, stative input-verbs (see section 4.1) will be incompatible with What- $X$-did-to- $Y$-tests. 
(b) What happened to the US was two small countries outvoted them. / What two small countries did to the US was outvote them. [compare (17b)]

(c) What happened to the resolution was the shareholders meeting outvoted it. / What the shareholders meeting did to the resolution was outvote it. [compare $(17 \mathrm{c})]$

Similarly, the distinction between in-and for-adverbials is claimed to allow for testing for telicity, or the distinction between processes and accomplishments (cf. Dowty 1979), with accomplishment structure taken as a hallmark of resultative constructions. As shown in (19), an out-derivative such as outclass is attested with both of these adverbials: in in (19a) gives rise to the interpretation that the tennis players in question lost a match, while for in (19b) leads to an interpretation that Boetsch had merely been dominated for a certain amount of time (both from iWeb):

(19) (a) The first all-Australian women's pairing to make the title match in Paris in 46 years, Dellacqua and Barty were outclassed in 66 minutes.

(b) After being thoroughly outclassed for ten straight minutes by an opponent no one expected him to defeat, a battered and bruised Tim Boetsch trudged back to his corner $[\ldots]$

Whatever the general merit of these aktionsart- or resultativity-tests may be, their mixed results for out-prefixed forms with the same input-verbs speak in favor of assuming an underspecified semantics for the construction. In light of the attested corpus examples discussed in this section, we are overall faced with a far less homogeneous picture than any of the approaches introduced in section 2 appear to suggest. There are at least five observations a more comprehensive analysis of out-prefixation will have to capture:

- While many examples suggest comparative interpretations, comparison does not arise on the basis of events or verbs, but on the basis of scalar dimensions evoked by the base in combination with what is given in the surrounding context.

- This can explain why comparative readings are possible in cases for which the Objectargument clearly does not participate in the same kind of event as the Subject-argument. In some cases, Objects can arguably be coerced into thresholds.

- The possibilities of such comparative readings are not unrestricted, though, and rely on similarity restrictions.

- There are also cases for which no comparative interpretations are easily available. In these cases, resultative readings are the only ones suggesting themselves.

- While such resultative interpretations are compatible with most of the examples that also allow for comparisons along scalar dimensions, resultative readings become more elusive the less concretely a competition between Subject- and Object-arguments can be construed.

To summarize, this section has shown that out-prefixed verbs admit far more flexibility regarding their possible interpretations than commonly assumed. We will now turn to 
selectional restrictions proposed in the literature. Upon closer inspection, this is another area in which postulated constraints prove far too restrictive.

\section{Selectional restrictions}

Several authors discuss out-prefixation primarily regarding potential restrictions on the morphological base. In this section, I will summarize some of the main claims brought forth and show that they fall short of the data in several respects. Just as out-prefixation has been shown to admit more flexibility regarding possible interpretations, it is more promiscuous than often assumed regarding its possible input. The literature uses out-prefixation and alleged base restrictions for two largely, although not entirely, independent reasons: (i) the putative suitability of the construction as a test environment for verb classification; (ii) the theoretical unease in some morphological models that comes with allowing proper category-changing prefixes in English. While neither of these two vantage points is of core interest to this section, the following proves several basic assumptions in the literature to be too restrictive. We will start with verbal bases in section 4.1, followed by non-deverbal formations in section 4.2.

\subsection{Verbal bases}

Regarding verbal bases, out-prefixation is at times said to be sensitive to aktionsart (cf. Filip 2011 for an overview) and to verb complexity (cf. Rappaport Hovav \& Levin 1998). For example, it is claimed that it only admits activity-verbs (see, e.g., Bresnan 1982: 168f.; Roberts 1985: 413f.) or activities/processes and semelfactives (cf., e.g., Levin 1999; Baker 2019). ${ }^{8}$ Activities or process-verbs indeed appear to make up the better part of the data, as in (20a), and semelfactives also occur regularly, as in (20b) (all examples attested in iWeb):

(20) (a) outplay, outrun, outsing, outdance, outwalk, outsleep, outlaugh etc.

(b) outblink, outsneeze, outhit, out-tug, out-burp, outfart, outrebound etc.

However, we also find stative examples, although clearly less frequently:

(21) (a) And speaking of pain, she out-knows me. (COCA)

(b) At about 6 -foot-3, he outweighs me by an easy 80 pounds... (COCA)

(c) I expect my Scamp to outlast several tow vehicles. (iWeb)

(d) ...in a league where the plan is to out-run and to out-want your opponents, that what you are able to bring from the substitutes bench is all. (iWeb)

(e) Besides the generally known quality of a sniper it is especially important to be able to outsit the enemy. (iWeb)

(f) ....Jean Le Breton, France's Secretary of State under King Francis I, decided to build a new magnificent castle that would outstand other medieval fortresses. (iWeb)

\footnotetext{
${ }^{8}$ Or inherently perfective events in the parlance of Williams (1992: 275f.).
} 
As argued by Baker (2019: 580), state-verbs may allow for reconceptualization as processes, and therefore serve as bases for out-. This is difficult to see in the examples in (21a-c), which are clearly stative uses of the respective verbs, in that they lack a dynamic component. Although far from self-evident, the use of out-want in (21d) arguably allows for some form of dynamic reading, as it denotes behavior and is thus characterized by change. As in $(21 \mathrm{e}, \mathrm{f})$, spatial configuration verbs also feature as input to out-, although their inclusion in the stative category is controversial (cf. e.g. Dowty 1979: ch. 3.8.3; Levin \& Hovav 1995: 130f.). We find several more stative readings of $o u t$-verbs as complex words if nominal and adjectival bases are included, as in (22a,b), where the natural interpretations are 'have more men/women' and 'be brighter', respectively (see below for non-deverbal examples in general).

(22) (a) The prosecution, on the other hand, has these 43 lawyers, hundreds of investigators. We are out-manned, out-womaned, out-moneyed at every turn in this case. (COCA)

(b) The flowers are brighter though (you can't out-bright hot pink). (iWeb)

Verbs commonly classified as achievements in the Vendler-Dowty-classification appear to be in fact very rare, although not entirely excluded, as in (23) (see Tolskaya 2014 for claims to the contrary).

(23) (a) It wouldn't be a surprise that years or maybe months from now, video marketing/ video selling may just outwin all other strategies in play right now. (iWeb)

(b) Not only was I able to quickly and easily undo the backlash in my friend's line, but I was also able to outspot him when it came to seeing fish at a distance. ${ }^{9}$

(c) This wouldn't help all cases but would at least eliminate those instances when all you need to do is destroy an arty and it outspots you and kills you. (iWeb)

Note that it is not necessarily the case that punctual achievements only allow for cardinality construals, i.e. repetitive or habitual readings: outspot in (23b), for example, is compatible with interpretations in which the Subject-argument spots fish at a distance more frequently (repetitive) than the Object-argument, as well as with interpretations in which the Subject-argument spots fish quicker/earlier. The 'earlier/ quicker'-reading appears to be the only one possible in (23c). In turn, this time-related comparison is not based on SPEED as a property of events, but rather on their occurrence in time in general. Regarding possible comparisons in both these cases, it is the events as such that are either located in time or quantified over, rather than some property dimension.

Constraints similar to the ones on achievements are postulated with respect to verb complexity (cf. Levin 1999, 2009; Beavers \& Koontz-Garboden 2012). Accordingly, verb roots with lexicalized scalar changes or results do not feature as input to out-prefixation, which the authors take as a diagnostic for manner-result-complementarity.

9 Wright, Peter. Dec 1996. Sea-keeping. Motor Boating \& Sailing 178(6), 31. Retrieved from http://books.google. com. 
Roughly, the assumption is that out- functions as an Object-deletion and retransitivization context for verbs that can be used both transitively and intransitively, such as drink or eat. In turn, verbs with presumably lexicalized results are predicted to disallow such Object-deletion and, in consequence, also out-prefixation (see also Tolskaya 2014 for a less wholesale dismissal of scalar-result-verbs). For example, the following (made-up) data are judged bad by some of the above authors:

(24) (a) ??Kim outshattered the other bottle-shatterer. (=ex. 19 in Beavers \& Koontz-Garboden 2012)

(b) Robot Bender will ?out-flatten / ?out-straighten all the robots at the robot Olympics. (=ex. 39 in Tolskaya 2014) ${ }^{10}$

While, again, not particularly frequent, there are attested cases of result-verbs as in (25):

(25) (a) Coke's biggest failure, the so-called "New Coke" of 1985, was an attempt to "out-sweeten" Pepsi which had ten more calories of sugar, by upping the sugar in Coke to 156 calories. (iWeb)

(b) The next two sets both went Souza's way, the Brazilian twice outbreaking the Argentine to make it 76(4) 76(5) $5757 \ldots{ }^{11}$

(c) Your Theorie offers premiere products that create better hair. Since the beginning, they have been developing superior technology to design tools and products that could out-straighten, out-curl, out-style, out-dry, and [sic] all others. (iWeb)

(d) An aluminum radiator will out-cool a copper brass radiator of similar size and construction by at least $40 \%$. (iWeb)

(e) Even that word fermentable is loaded, because some of what is fermentable to Belle Saison is not fermentable to Lalvin D-47, and Brett C should be able to outferment both of them if pitched post-primary fermentation. ${ }^{12}$

(f) "Bojemoi, that woman has toes that could outcrush a boa constrictor!" he gasped. $^{13}$

The base verbs in (26) are certainly not all alike. For example, to sweeten, to dry, and to cool are what have been termed degree achievements (cf., e.g., Kennedy \& Levin 2008). The adjectival bases map to either open (cool, sweet) or closed scales (straight, dry) (cf., e.g., Kennedy \& McNally 2005; Kennedy 2007), while to crush or to break are often considered proper change-of-state verbs (cf., e.g., Rappaport Hovav \& Levin 2002). Although differences between these classes as possible input for out-prefixation have been suggested (cf. Tolskaya 2014), the important point here is that all of the classes are attested in their causative variants that would conventionally take an Object that

10 This example is not untypical for invented data for grammaticality judgements: essentially, it is nearly impossible to tell what the sentence is supposed to mean in the first place, which blurs the line between '(un)grammaticality' and pragmatic/semantic (un)interpretability.

11 www.daviscup.com/en/news/200583.aspx

12 reddit.com/r/Homebrewing/comments/5yffpv/mash_fermentability_and_temp_possibility_of/

13 Bishop, David. 2006. Honour be Damned. Black Flame Publishing. Retrieved from http.//books.google.com, n.p. 
undergoes change ((25a) is arguably ambiguous in this regard). Thus, in (25b), it is Souza who breaks someone in tennis, ${ }^{14}$ in $(25 \mathrm{c})$ it is tools/products that straighten hair, and in (25f) it is the toes that could crush something.

On the assumption that psych-verbs are a special case of result- or change-of-state-verbs (see, e.g., Plag et al. 2018), many more such examples can be found, as in (26) (all from COCA):

(26) (a) This screwball premise lives or dies by the chemistry between Pine and Hardy, who are too busy trying to out-appeal one another to make the buddy dynamic click.

(b) As Priest returned the Black Panther to his roots as a political figure as much as a superhero, he became a hugely capable character able to out-think Iron Man, out-fight Captain America and out-threaten Wolverine.

(c) Occupiers can thus be successful without need of any specialized counterinsurgency methods or tactics if they are willing to out-terrorize the insurgents...

(d) But if the 41-year-old Johnson has outentertained the 61-year-old Riley, he has certainly not outcoached him.

A final alleged restriction on verbal bases concerns the agentive nature of the construction: accordingly, both the input verb and the interpretation of the complex out-form have to select AGENTS as Subject (see Talmy 2000: 260f.). Given that stativity and agentivity are usually regarded as mutually exclusive, this constraint has already been shown to make wrong predictions above. However, we also find non-agentive examples of process-verbs as in (27) (which possibly explains the fact that, for example, Tolskaya (2014) and Baker (2019) avoid the term activity):

(27) (a) ...the Jeep Renegade should outscoot every competitor with the exception of the Nissan Juke... (iWeb)

(b) ...Dr. Chalongphob adds, "it's now clear that our economic growth out-paced our political maturity. (COCA)

(c) I'd think the LCD panel itself will greatly outlive the backlight... (iWeb)

To summarize, the discussed restrictions on aktionsart and event complexity of the respective verbal bases of out- cannot hold in their strong versions. All aspectual verb classes are attested as input and neither bases nor the complex forms have to be agentive. Although there are possible preferences that, roughly, map to said restrictions, these cannot be hard grammatical constraints. While this section has looked at selectional restrictions of verbal subclasses, the following sections deal with more general word class constraints.

${ }^{14}$ To break here means to win a game as the receiving player by breaking the opponent's serve. 


\subsection{Word class restrictions}

Regarding nominal and adjectival bases, Bauer et al. (2013: 343) provide several corpus examples for which they claim that out- in the reading discussed here is indeed category-changing, for example deadjectival out-absurd, outcute or outsmart and denominal out-Birth, out-Bubba or outdollar. Similarly, Bauer \& Huddleston (2002: 1679) acknowledge the regular occurrence of denominal formations. The abovementioned unease in the literature with category-changing prefixes rests on the assumption that such cases would violate the Righthand Head Rule (see Williams 1981; Hammond 1993), taken as a typological feature of Germanic languages in general (see, e.g., Kastovsky 2006). For example, Nagano (2011) argues at length that there are both synchronic and diachronic arguments in favor of assuming noun-to-verb or adjective-to-verb conversion prior to out-prefixation. ${ }^{15}$ McIntyre (2015) claims that denominal out-formations occur rarely, while Levin (1999: fn.11) and Irube (1984: fn.5) state that deadjectival out- is so rare as to be negligible.

Consider, however, the denominal examples in (28):

(28) (a) Global big data competitors can out-technology you, but they can't out-human you. (iWeb)

(b) [...] he outboxed, outpointed and outshowmanshipped a long-reigning middleweight champion despite serious disadvantages in height [...] (COCA)

(c) There was an old boy with 'a lifetime of badges' on his hat. Excuse me, but we have those too. (Step forward Lil Kemp who could outbadge him any day.) ${ }^{16}$

(d) I went downtown to check out the crime scene, but that douche from the FBI out-badged me! ${ }^{17}$

(e) The Trail Blazers can outscore (they're No. 3 in the league in points and the only team with six players averaging in double figures), outrebound (they're No. 4 in rebound margin), outdefend (they're No. 3 in the West in points allowed) and outbench opponents (their reserves have outscored 11 of 18 opponents). (COCA)

The data in (28) are problematic for a conversion pre-prefixation approach. For example, technology in (28a) and showmanship in (28b) are not listed as verbs in the $O E D$, nor do they occur tagged as verbs in COCA in any potential word form. To badge exists according to the $O E D$ (roughly, 'mark with/attach/present a badge'), which is possibly the intended use in (28d), but the interpretation in (28c) is clearly different: here, outbadge indicates a cardinality reading, i.e., 'have more badges'. Similar considerations hold for bench in (28e), with outbench apparently intended as roughly meaning 'having had more successful players coming off the bench'. My current

\footnotetext{
15 This obviously does not only concern out-, but also other English prefixes such as be-, de-, dis-, en-, or un-, as in, for example, belittle, delouse, or disbar. See, for example, Stiebels (1996: ch. 9) and Olsen (1990) for assumptions that conversion has to feature pre- or simultaneous with prefixation in similar cases in German.

16 pinkun.com/opinion/run-in-is-more-nail-biting-than-expected-1-642935.

17 urbandictionary.com/define.php?term=Out-badged
} 
database of denominal out-formations includes 264 items, largely from the $O E D$, COCA, and iWeb, out of which 138 ( $52 \%$ ) do not feature verbal base forms in the $O E D$ or forms with clearly different readings only. There is also quite a variety of semantic classes to be found in the data: for example, the bases in $(28 \mathrm{a}, \mathrm{b})$ are abstract nouns (technology, showmanship), while those in $(28 \mathrm{c}, \mathrm{e})$ are concrete object nouns (badge, bench). As in (29)-(31), three kinds of nominal base appear particularly frequently, namely proper names, attitudinal nouns, and role nouns (all examples from COCA):

(29) PROPER NAMES

(a) $[\ldots]$ they're surely going to try to figure out a way to out-Ikea Ikea.

(b) out-Columbine, out-Jesus, out-Portland, out-Spock, out-Trump, out-Wal-Mart etc.

(30) ATTITUDINAL NOUNS

(a) Your basic hairy-chested guy who wrangles rattlers may find himself out-machoed by a half-pound of cute, wiggly-nosed fluff.

(b) out-wunderkind, out-thug, out-wonk, out-nimbyed, out-snob, outjunk etc. (31)

(31) ROLE NOUNS

(a) "Out-priesting the priests" isn't the same as embracing the vocation to lead through service, as Jesus did.

(b) out-bourgeois, out-lawyer, outjockey, out-pander, outdaughter, out-troll etc.

Unlike object nouns, such as badge above, that (can) give rise to cardinality interpretations, these cases usually refer to often underspecified stereotype readings. Thus, the examples in (29) roughly mean 'exceed in some property typical for X', those in (30) are interpreted as 'behave more like an X typically behaves' and in (31) 'act more stereotypically X-like'. Moreover, many such formations include contextual licensing, such as establishment of a competition context via other out-verbs, as in the e-example in (28), or the base occurring in Direct Object position of the construction as in (29) and (31) (see Marchand 1969: 97 for the use of proper names as both out's base and the construction's Direct Object). Occasionally, we also find phrasal bases as in out-big-man, out-good-old-boy (both from iWeb) or out-cheap-shot (COCA) with characteristics similar to attitudinal or role nouns.

Turning to adjectival bases, consider the data in (32) (all from iWeb):

(32) (a) In my group therapy sessions, each attendee tries to out-sad the last, and one-downers are much worse than one-uppers.

(b) It's not everyday Brown gets a competition for nicest, friendliest, most clappiest man in the room. But how do you out-nice a Mormon?

(c) They were also exhausting, turning any and all social situations into comedic skits, each of them trying to out-funny me and everyone else in the room.

(d) It appears the thunder and the gypsy punk CD playing in the tent are attempting to out-obnoxious one another. 
The bases in the deadjectival use illustrated in (32) form the most common pattern found in the data: notionally, sad, nice, funny and obnoxious are all EVALUATIVE or HUMAN PROPENSITY adjectives (see, e.g., the classification in Dixon 1982). Making use of test environments such as occurrence with a progressivized copula (She is being nicel funny/??tall) or command imperatives (Be nicelfunny/??tall), these classes are often claimed to have an inherent dynamic potential. Thus, they are more verb-like than typical stative adjectives such as, for example, COLOR- or DIMENSION-adjectives (cf. Lakoff 1966; Quirk 1985; Ferris 1993). Other adjective classes are less frequently attested as bases, for example, PHYSICAL PROPERTY, DIMENSION, or TASTE adjectives as in (33).

(33) (a) A bunch of noise going at the same time. You out-louded the next person, and then a member might get mad... (COCA)

(b) Why don't you play him at the 3? Because 3's might outquick him and confuse him. (COCA)

(c) Craft brewers outbitter one another with double, triple, imperial IPAs and fight pun for pun with their names... ${ }^{18}$

Practically all of the 80 examples in my data are clearly gradable according to established tests. Following, for example, Kennedy \& McNally (2005) and Kennedy (2007), gradable adjectives lexicalize scales and it is the respective dimensions of these scales that suggest themselves for establishing comparisons. In consequence, interpreting deadjectival forms unsurprisingly appears more straightforward than for many of the denominal cases above (as well as for many verbal forms; see section 3). Thus, in (33) above, out-louded is naturally interpreted as 'outdo by being louder/in LOUDNESs', outquick as 'outdo by being quicker/in SPEED', and outbitter as 'outdo by being more bitter/in BITTERNESS'.

\subsection{Summary}

Overall, this section has shown out-prefixation to be highly promiscuous. Several of the selectional restrictions brought forth in the literature, such as bans on non-agentive or result-verbs, cannot easily be upheld upon consulting larger corpora such as COCA or iWeb. Non-deverbal out-formations are clearly much more common than claimed by several authors and many examples exist for which converted bases are not independently attested. Analyses that assume conversion prior to prefixation, such as the one in Nagano (2011), thus appear to primarily serve the purpose of safeguarding a theoretical desideratum via an empirically dubious mechanism. This section has also shown that the general interpretation of non-deverbal out-verbs is fairly similar to deverbal formations, although stative readings appear more common with, in particular, denominal forms. At the same time, this situation makes formulating or establishing clear-cut restrictions particularly difficult. It thus appears to call for a treatment that analyzes morphological processes not primarily input-oriented but rather conceptually and semantically output-oriented (as advocated by, for example, Plag 2004).

18 Bostwick, William. 2015. The Brewer's Tale: A History of the World According to Beer. Retrieved from http.//books.google.com, n.p. 
The following section will summarize and generalize over the findings of sections 3 and 4. Doing so, it will spell out some of the challenges and requirements a formalization of out-prefixation that is more adequate than the ones critiqued in this article will have to meet.

\section{Generalizations and outlook}

This study's core finding on the semantics of out- is that it displays a degree of interpretational flexibility commonly not acknowledged in the literature. The vantage point has been a juxtaposition of two theoretical camps that analyze the construction as either inherently comparative or inherently resultative, respectively (see section 2). Corpus data lead to the assessment that, spelled out in their strong variants, neither of these camps' theoretical assumptions will suffice for capturing the data. The perhaps somewhat unsatisfactory conclusion, however, has to be that the tension between the two opposed analyses cannot easily be dissolved. Rather, weak resultativity and comparison are both central to out-'s semantics (see section 3).

Historically, the comparative sense of out - is to a degree obscure. The few claims in the literature with regard to out-'s diachronic development suggest that a double duty of denoting degree and resultativity has characterized the construction's nature from its infancy on. Most authors agree that the relevant sense developed in the fourteenth and fifteenth centuries and became fully productive with verbal bases by 1600 . Moreover, it is assumed to have derived from core locative cases via an intermediary step of semantic change in Middle English (cf. Brinton 1988: ch. 5; Nagano 2011). As attested by the examples in (34), this intermediary form, apparently no longer productive in Present-day English, already includes the merger of elements of degree modification and resultative semantics (examples adapted from Nagano 2011: 68):

(34) outbaken 'to bake sth. thoroughly'; out-tire 'to tire (sth.) completely'

The completive semantics suggested by the paraphrases in (34) includes both an intensifying, scalar meaning component, such as a high degree of tiredness, as well as the result state the affected argument enters, such as reaching the most extreme state of tiredness. However, the development of the comparative meaning component of modern out- appears unusual given cognates in other West Germanic languages. For example, Motsch (2004: ch. 2) and Fleischer et al. (2012: 406ff.) provide several word-formation patterns for the German verb particle aus- 'out-'. These include senses denoting location/direction (ausgraben 'to dig out'), completion (etw. ausleuchten 'illuminate sth. completely'), result (etw. ausarbeiten 'finalize sth.'), negatively evaluated sound emission ( $j m d$. ausbuhen 'to boo so.') or end of an event and transition to a state of rest (ausrollen 'to roll to a stop'). For Dutch, reference works include locative-directional (uitademen 'to breath out'), various resultative-completive (uitspreiden 'spread out'; uitsluiten 'exclude'), or negatively evaluated affective (uitschelden 'to scold') meanings (cf.; de Haas \& Trommelen 1993: 113ff.; Blom 2005: 182ff.). While completive and resultative senses are thus found for Dutch and 
German cognates of out-, no clear-cut equivalent to a comparative sense seems available. In turn, the closest such equivalent is found with cognates of over-, as in German jmd. überstimmen ('to outvote s.o.') and jmd. überbieten (to 'over-/outbid s.o.') (see Fleischer et al. 2012: 393f.) or Dutch overschreeuwen ('to outshout') and overleven ('to outlive') (cf. Blom 2005: App.2).

Neither the construction's diachrony nor this brief cross-linguistic excursus have strong explanatory power on their own. They do, however, underline that notes of caution are in order regarding approaches that consider comparison or surpassment as the sole semantic components of out-prefixation. Modeling out-prefixation as agentive, comparing two events of the same kind (in particular co-indexing them or assuming deletion of one form of the base base verb), and thus demoting Object-arguments to mere thresholds make wrong predictions (pace, for example, Talmy 2000; Tolskaya 2014; Ahn 2016). Comparison is based on dimensions, sameness of events is not always necessary and comparative interpretations do not suggest themselves in all cases. Dimension-based comparison, however, still relies on incommensurability-restrictions and requirements for successful comparison are to be found at the level of more general event types. This needs to be spelled out in detail in future work to allow for more general claims (possibly going beyond questions of how out- behaves) of what, or which level of description, is best suited for comparison. Still, the notion of comparison or exceeding some threshold is found in the clear majority of cases. Therefore, semantic analyses that assume pure, Object-related resultative structures for out-prefixation are also undesirable. Providing an unspecific label for the Object-argument's result state, such as OUTDONE without further specification, and relegating the comparative nature of most of the examples to an idiosyncratic constructional feature misses out on unquestionable generalizations that should be part of the construction's core semantic contribution (against, for example, the semantics advocated by McIntyre 2003).

Section 3 ended on the assessment that out-prefixation allows for a cline of different, yet related interpretations. This, however, does not speak in favor of different constructions or prefix senses. First, the better part of the data is compatible with both comparative and (weak) resultative semantics, i.e. on the assumption of distinct senses, both would co-occur in most cases. In contrast, it is merely the edges of the described continuum of interpretations for which one or the other is (more) difficult to trace. Second, this has been shown to hold even with different tokens of the same input-verb to out- (see outvote in the examples in (17)). Now, if there is only one prefix out-, at least in the sense described in this study, if the system of out-prefixation is less restrictive than assumed in the literature, and if it allows for the simultaneous availability of resultative and comparative semantics, what are the possibilities and challenges of modeling such behavior? And how does it relate to the locative senses attested for out- as a prefix?

This, obviously, is also a matter of the theorist's preferred model of morphology or derivational semantics. For example, morpheme-based or word syntax approaches that take affixes to be independent signs (cf., e.g., Lieber 1992) would typically take the route of searching for core meanings of different prefix-senses (cf. Rainer 2014 for an overview). Semantically typically committed to compositionality, this core meaning 
would, for example, combine with bases via unification to derive the observed meanings of complex words (see Zinova 2016 for such an attempt with similar cases of Russian prefixes). While the actual behavior of locative out- is obviously an empirical question (and one thus far not addressed in the literature), it is certainly not impossible to see commonalities between the locative and 'comparative' versions of out-. The counterparts to scalar-comparative and weak change-of-state readings in the latter case would be the PATH- and CHANGE-OF-LOCATION components inherent to locative examples. The analogy with causative-resultative interpretations can also be read from the variable transitivity of locative out-; in the transitive variant (see (35a)), it is the Object-argument that appears to undergo the change-of-location, while it is the Subject-argument in the intransitive construction as in (35b) (both from COCA):

(35) (a) Our volcanos outgas enough $\mathrm{CO2}$ to keep the biosphere in balance.

(b) Water and hydrocarbons outgas from the new hardware when exposed to the vacuum of space.

However, the notion that out- as a prefix has a concrete, albeit highly abstract, meaning on its own is theoretically not necessarily desirable, and empirically problematic (for general critiques of such an approach, see Booij 2010 and Rainer 2014). For example, reducing an alleged prefix meaning to the transgression of a threshold makes it difficult to set apart different prefixes of prepositional origin, such as out- and over-, without acknowledging construction-specific semantics for individual senses (see Williams 1992; Tolskaya 2014; Zinova 2016 for attempts to this end). As argued in section 3, out-prefixed forms include three sub-events via the CORRELATED EVENTUALITIES that Object-arguments are participants of. In case this generalization is correct, this differs from locative out-, which appears to include only two sub-events. Moreover, the flexibility of different interpretations along a continuum of (more) comparative and (more) resultative readings of "comparative" out- has been shown to heavily rely on contextual information as well as more general knowledge sources. Although this poses fundamental questions as to what kind of information is to be included in a model of derivational semantics, word- and/or constraint-based approaches to morphology that do not regard affixes as signs in the narrow sense are arguably more promising (cf., e.g., Booij 2010; Bonami \& Crysmann 2016; Lieber 2016; Plag et al. 2018). These allow for spelling out complex and idiosyncratic semantic information and offer the possibilities of fine-grained meaning differentiation, as well as creating networks of related interpretations via hierarchies of schematic lexeme formation rules.

A further potential advantage of such schematic hierarchies is found with respect to the category-changing potential of out-. Non-deverbal bases have been shown to occur more regularly, more frequently and with a larger variety of possible base classes than often assumed (see section 4.2). Some frequent patterns, such as dynamic adjectives or proper names, possibly allow for analyses parallel to relatively typical conversion phenomena. Intricate problems arise with other input forms, such as object nouns (e.g. badge) or abstract nouns (e.g. technology). Irrespective of (unconvincing) assumptions concerning possible pre-prefixation conversion for such examples, the required 
meaning shifts call for semantic explanations as to how and when we arrive at interpretations that include scalar attributes or quantify over entities. As suggested by one reviewer, conversion may also occur simultaneously with prefixation (see also Stiebels 1996: ch. 9). This kind of analysis may be less dubious empirically, in that it does not rely as much on the existence of attested converted bases. However, it does not offer a straightforward solution to the problem of interpretation, either, and it raises the question of what the concrete difference would be between category-changing prefixation proper, on the one hand, and conversion and non-category-changing prefixation occurring simultaneously on the other. Thus, further questions for future research arise: are these possible coercion phenomena of the non-verbal base that are induced by the constructional semantics of out-prefixation as well as contextual information? Do we find inherent attributes in the semantic make-up of different classes of adjectives or nouns that allow for predictions regarding possible interpretations?

Further, it has been shown that the largely non-critical use of out-prefixation as a test environment for verb-classification is problematic upon closer inspection (see section 4.1). All aktionsart-classes can be found as input to out- (on the assumption that aktionsart is at least indirectly related to lexical items; see van Valin \& LaPolla 1997; Filip 2011). Also, different kinds of change-of-state verbs, including in their causative variants, do occur as input to out-. Given this promiscuity, other research questions emerge: how far does lexical aspect allow for predictions on the kind of interpretation out-contexts allow? For example, the rare cases of achievements, such as outspot, do not seem to induce property scale readings, which appears to speak in favor of such a possibility (see Zinova 2016 for arguments in this vein for Russian). What are the repercussions of these findings for the obligatoriness of argument realization and possible Object dropping of change-of-state verbs (see Rappaport Hovav \& Levin 1998 and Goldberg 2001 for different claims in this respect)?

\section{Conclusion}

This study has looked at the semantics of verbal out-prefixation in its, presumably, comparative sense. The main objective has been to provide a more full-fledged analysis based on a data set of corpus-attested examples that is both larger and more accurate than the ones previous accounts have relied on. The data have been employed to critically assess theoretical treatments of the construction's semantics and claims regarding its alleged selectional restrictions. Several of these claims have to be discarded on the basis of this assessment. This does not entail that modeling and/or formalizing out-'s semantics has become in any way an easier task: the construction's interpretational flexibility and its promiscuity regarding potential input rather pose a range of intricate questions and challenges not paid attention to in earlier approaches. Although this article has not attempted any concrete formalization, the emerging picture speaks in favor of a far less restrictive system. This holds both in terms of the attested interpretations of out-prefixed forms as well as the attested bases. 
Author's address:

SFB 991

Heinrich-Heine-Universität Düsseldorf

Universitätsstr. 1

40204 Düsseldorf

sven.kotowski@uni-duesseldorf.de

\section{References}

Ahn, Byron. 2016. Severing internal arguments from their predicates: An English case study. Talk at the annual meeting of the LSA, Washington DC; 8 January 2016.

Asher, Nicholas. 2011. Lexical meaning in context: A web of words. Cambridge: Cambridge University Press.

Baker, James. 2019. Split intransitivity in English. English Language and Linguistics 23(3), 557-89.

Barsalou, Lawrence W. 1983. Ad hoc categories. Memory \& Cognition 11(3), 211-27.

Bauer, Laurie. 2003. English prefixation: A typological shift? Acta Linguistica Hungarica 50(1-2), 33-40.

Bauer, Laurie \& Rodney Huddleston. 2002. Lexical word-formation. In Rodney Huddleston \& Geoffrey K. Pullum, The Cambridge grammar of the English language, 1621-1721. Cambridge: Cambridge University Press.

Bauer, Laurie, Rochelle Lieber \& Ingo Plag. 2013. The Oxford reference guide to English morphology. Oxford: Oxford University Press.

Beavers, John \& Andrew Koontz-Garboden. 2012. Manner and result in the roots of verbal meaning. Linguistic Inquiry 43(3), 331-69.

Bierwisch, Manfred. 1989. The semantics of gradation. In Manfred Bierwisch \& Ewald Lang (eds.), Dimensional adjectives. Grammatical structure and conceptual interpretation, 71-261. Berlin and Heidelberg: Springer.

Blom, Corrien. 2005. Complex predicates in Dutch: Synchrony and diachrony. Utrecht: LOT.

Bonami, Olivier \& Berthold Crysmann. 2016. Morphology in constraint-based lexicalist approaches to grammar. In Andrew Hippisley \& Gregory T. Stump (eds.), The Cambridge handbook of morphology (Cambridge Handbooks in Language and Linguistics), 609-56. Cambridge: Cambridge University Press.

Booij, Geert E. 2010. Construction morphology (Oxford Linguistics). Oxford: Oxford University Press.

Bresnan, Joan. 1982. Polyadicity. In Joan Bresnan (ed.), The mental representation of grammatical relations (MIT Press series on Cognitive Theory and Mental Representation), 149-72. Cambridge, MA: MIT Press.

Brinton, Laurel J. 1988. The development of English aspectual systems: Aspectualizers and post-verbal particles (Cambridge Studies in Linguistics 49). Cambridge: Cambridge University Press.

Davies, Mark. 2008. The Corpus of Contemporary American English: 400+ million words, 1990-present. Available online at https://corpus.byu.edu/coca/. www.americancorpus.org/

Davies, Mark. 2018. The 14 billion word iWeb Corpus. Available online at https://corpus.byu.edu/ iWeb/

Dixon, R. M. (ed.). 1982. Where have all the adjectives gone? Berlin and New York: De Gruyter Mouton. 
Doetjes, Jenny. 2010. Incommensurability. In Maria Aloni, Harald Bastiaanse, Tikitu de Jager \& Katrin Schulz (eds.), Logic, language and meaning (FoLLI Publications on Logic, Language and Information), 254-63. Berlin: Springer.

Dowty, David R. 1979. Word meaning and Montague grammar: The semantics of verbs and times in generative semantics and in Montague's PTQ (Studies in Linguistics and Philosophy). Dordrecht: Springer.

Ferris, Connor. 1993. The meaning of syntax: A study in the adjectives of English. London: Longman.

Filip, Hana. 2011. 48. Aspectual class and aktionsart. In Klaus von Heusinger, Claudia Maienborn \& Paul Portner (eds.), Semantics (Handbücher zur Sprach- und Kommunikationswissenschaft/ HSK]), Berlin: De Gruyter.

Fleischer, Wolfgang, Irmhild Barz \& Marianne Schröder. 2012. Wortbildung der deutschen Gegenwartssprache, 4th edn. Berlin and Boston: De Gruyter.

Goldberg, Adele E. 2001. Patient arguments of causative verbs can be omitted: The role of information structure in argument distribution. Language Sciences 23, 503-24.

Goldberg, Adele E. \& Ray Jackendoff. 2004. The English resultative as a family of constructions. Language 80(3), 532-68.

de Haas, Wim \& Mieke Trommelen. 1993. Morfologisch handboek van het Nederlands: Een overzicht van de woordvorming. The Hague: SDU.

Hammond, Michael. 1993. On the absence of category-changing prefixes in English. Linguistic Inquiry 24, 562-7.

Irube, Kaneharu. 1984. Argument structure and the out-prefixation. English Linguistics 1(1), 105-22.

Jackendoff, Ray. 1997. Twistin' the night away. Language 73(3), 534.

Kagan, Olga. 2015. Scalarity in the verbal domain: The case of verbal prefixation in Russian. Cambridge: Cambridge University Press.

Kastovsky, Dieter. 2006. Vocabulary. In David Denison \& Richard M. Hogg (eds.), A history of the English language, 199-270. Cambridge: Cambridge University Press.

Kennedy, Christopher. 1997. Projecting the adjective: The syntax and semantics of gradability and comparison. PhD dissertation, University of California, Santa Cruz.

Kennedy, Christopher. 2007. Vagueness and grammar: The semantics of relative and absolute gradable adjectives. Linguistics and Philosophy 30(1), 1-45.

Kennedy, Christopher \& Beth Levin. 2008. Measure of change: The adjectival core of degree achievements. In Louise McNally \& Christopher Kennedy (eds.), Adjectives and adverbs: Syntax, semantics, and discourse (Oxford Studies in Theoretical Linguistics 19), 156-82. Oxford: Oxford University Press.

Kennedy, Christopher \& Louise McNally. 2005. Scale structure, degree modification, and the semantics of gradable predicates. Language (81), 345-81.

Keyser, Samuel J. \& Thomas Roeper. 1984. On the middle and ergative constructions in English. Linguistic Inquiry 15(3), 381-416.

Kipper, Karin, Anna Korhonen, Neville Ryant \& Martha Palmer. 2008. A large-scale classification of English verbs. Language Resources and Evaluation 42(1), 21-40.

Lakoff, George. 1966. Stative adjectives and verbs in English: Report NSF-17. Cambridge, MA: Harvard University Computation Laboratory.

Lehrer, Adrienne. 1995. Prefixes in English word formation. Folia Linguistica 29(1-2), 133-48.

Levin, Beth. 1993. English verb classes and alternations: A preliminary investigation. Chicago: University of Chicago Press.

Levin, Beth. 1999. Objecthood: An event structure perspective. In Sabrina J. Billings, John P. Boyle \& Aaron M. Griffith (eds.), Proceedings of CLS 35, vol 1: The Main Session, 223-47. Chicago: Chicago Linguistic Society. 
Levin, Beth. 2009. Lexical semantics of verbs VI: Assessing semantic determinants of argument realization [lecture notes]. https://web.stanford.edu/ bclevin/lsa09semdetproto.pdf.

Levin, Beth \& Malka Rappaport Hovav. 1995. Unaccusativity: At the syntax-lexical semantics interface (Linguistic Inquiry Monographs 26). Cambridge, MA: MIT Press.

Lieber, Rochelle. 1992. Deconstructing morphology: Word formation in syntactic theory. Chicago: University of Chicago Press.

Lieber, Rochelle. 2004. Morphology and lexical semantics. Cambridge: Cambridge University Press.

Lieber, Rochelle. 2016. English nouns: The ecology of nominalization (Cambridge Studies in Linguistics 150). Cambridge: Cambridge University Press.

Löbner, Sebastian. 1979. Intensionale Verben und Funktionalbegriffe: Untersuchung zur Syntax und Semantik von 'wechseln' und den vergleichbaren Verben des Deutschen: Zugl.: Düsseldorf, Univ., Diss., 1979 (Ergebnisse und Methoden moderner Sprachwissenschaft 7). Tübingen: Narr.

Los, Bettelou. 2008. Particles as grammaticalized complex predicates. In Maurizio Gotti, Marina Dossena \& Richard Dury (eds.), Syntax and morphology (Amsterdam Studies in the Theory and History of Linguistic Science ser. 4, Current Issues in Linguistic Theory 295), 157-79. Amsterdam: John Benjamins.

Maienborn, Claudia. 2007. Das Zustandspassiv: Grammatische Einordnung Bildungsbeschränkungen - Interpretationsspielraum. Zeitschrift für Germanistische Linguistik $35,83-115$.

Maienborn, Claudia. 2019. Flexible Bedeutungszuordnung im Lexikon: Polysemie Unterbestimmtheit - Uminterpretation. In Yasuhiro Fujinawa \& Jiro Inaba (eds.), Wie entsteht Bedeutung? Semantik zwischen Grammatik, Kognition und Kontext, 11-44. Munich: Iudicium Verlag.

Marchand, Hans. 1969. The categories and types of present-day English word-formation, 2nd edn. Munich: C. H. Beck.

McIntyre, Andrew. 2003. Preverbs, argument linking and verb semantics. In Geert Booij \& Jaap Marle (eds.), Yearbook of Morphology 2003, 119-44. Dordrecht and London: Kluwer Academic.

McIntyre, Andrew. 2007. Particle verbs and argument structure. Language and Linguistics Compass 1(4), 350-67.

McIntyre, Andrew. 2015. Denominal verbs. In Peter O. Müller, Ingeborg Ohnheiser, Susan Olsen \& Franz Rainer (eds.), Word-formation, 434-50. Berlin and Boston: De Gruyter.

Motsch, Wolfgang. 2004. Deutsche Wortbildung in Grundzügen, 2nd edn (Schriften des Instituts für Deutsche Sprache 8). Berlin: De Gruyter.

Nagano, Akiko. 2011. The right-headedness of morphology and the status and development of category-determining prefixes in English. English Language and Linguistics 15(1), 61-83.

OED. 2018. The Oxford English Dictionary online.

Olsen, Susan. 1990. Konversion als ein konkatenativer Wortbildungsprozeß. Linguistische Berichte 127, 185-216.

Plag, Ingo. 2003. Word-formation in English. Cambridge: Cambridge University Press.

Plag, Ingo. 2004. Syntactic category information and the semantics of derivational morphological rules. Folia Linguistica 38(3-4), 193-225.

Plag, Ingo, Marios Andreou \& Lea Kawaletz. 2018. A frame-semantic approach to polysemy in affixation. In Olivier Bonami, Gilles Boyé, Georgette Dal, Hélène Giraudo \& Fiammetta Namer (eds.), The lexeme in descriptive and theoretical morphology, 546-68. Berlin: Language Science Press.

Quirk, Randolph. 1985. A comprehensive grammar of the English language. London: Longman.

Rainer, Franz. 2014. Polysemy in derivation. In Rochelle Lieber \& Pavol Štekauer (eds.), The Oxford handbook of derivational morphology (Oxford Handbooks in Linguistics), 338-53. Oxford: Oxford University Press. 
Rappaport Hovav, Malka \& Beth Levin. 1998. Building verb meanings. In Miriam Butt \& Wilhelm Geuder (eds.), The projection of arguments (CSLI Lecture Notes), 97-134. Stanford, CA: CSLI Publications.

Rappaport Hovav, Malka \& Beth Levin. 2001. An event structure account of English resultatives. Language 77(4), 766-97.

Rappaport Hovav, Malka \& Beth Levin. 2002. Change of state verbs: Implications for theories of argument projection. In Julie Larson \& Mary Paster (eds.), Proceedings of the 28th Annual Meeting of the Berkeley Linguistics Society, 269-80.

Roberts, Ian G. 1985. The representation of implicit and dethematized subjects. $\mathrm{PhD}$ dissertation, University of Southern California.

Schröder, Anne. 2011. On the productivity of verbal prefixation in English: Synchronic and diachronic perspectives (Language in Performance 44). Tübingen: Narr.

Schwarzschild, Roger. 2008. The semantics ofcomparatives and other degree constructions. Language and Linguistics Compass 2(2), 308-31.

Solt, Stephanie. 2015. Measurement scales in natural language. Language and Linguistics Compass 9(1), 14-32.

Stassen, Leon. 1985. Comparison and universal grammar. Oxford: Blackwell.

Stiebels, Barbara. 1996. Lexikalische Argumente und Adjunkte: Zum semantischen Beitrag von verbalen Präfixen und Partikeln (Studia Grammatica 39). Berlin: Akademie Verlag.

Talmy, Leonard. 2000. Toward a cognitive semantics, vol. II: Typology and process in concept structuring (Language, Speech, and Communication). Cambridge, MA: MIT Press.

Tolskaya, Inna. 2014. Verbal prefixes: Selection and interpretation. PhD dissertation, University of Tromsø.

van Valin, Robert D. \& Randy J. LaPolla. 1997. Syntax. Cambridge: Cambridge University Press.

Williams, Darrell. 1992. English comparative compounds with OVER, UNDER and OUT. In Michael Bernstein (ed.), Proceedings of the Ninth Eastern States Conference of Linguistics (ESCOL), 272-81. Ithaca, NY: Cornell University.

Williams, Edwin. 1981. On the notions 'lexically related' and 'head of a word'. Linguistic Inquiry 12(2), 245-74.

Wunderlich, Dieter. 1997. Argument extension by lexical adjunction. Journal of Semantics 14(2), 95-142.

Wunderlich, Dieter. 2012. Operations on argument structure. In Claudia Maienborn, Klaus von Heusinger \& Paul Portner (eds.), Semantics, vol. 3 (Handbücher zur Sprach- und Kommunikationswissenschaft), 2224-59. Berlin: Mouton de Gruyter.

Zinova, Yulia. 2016. Russian verbal prefixation: A frame semantic analysis. PhD dissertation, Heinrich-Heine-University. 